\title{
Changing epidemiological trends of inflammatory bowel disease in Asia
}

\author{
Wee Khoon $\mathrm{Ng}^{1,2}$, Sunny H. Wong ${ }^{1}$, Siew C. $\mathrm{Ng}^{1}$ \\ ${ }^{1}$ Department of Medicine and Therapeutics, Institute of Digestive Disease, State Key Laboratory of Digestive Diseases and LKS Institute of \\ Health Science, The Chinese University of Hong Kong, Hong Kong, ${ }^{2}$ Department of Gastroenterology and Hepatology, Tan Tock Seng Hospital, \\ Singapore
}

Inflammatory bowel disease (IBD) has become more common in Asia over the past few decades. The rate of increase in prevalence of the disease varies greatly in Asia, with several countries in East Asia experiencing a more than doubled increase in IBD prevalence over the past decade. Historically, ulcerative colitis (UC) is more common than Crohn's disease (CD) in Asia. However, a reverse trend is beginning to appear in more developed countries in Asia such as Japan, Korea, and Hong Kong. While Asian IBD patients share many similarities with their Western counterparts, there are important differences with significant clinical implications. In Asia, there are more men with $\mathrm{CD}$, more ileo-colonic involvement in $\mathrm{CD}$, less familial aggregation, fewer extra-intestinal manifestations and worse clinical outcomes for older-onset patients with UC. These differences are likely related to the different genetic makeup and environmental exposures in different regions. Evaluation of the differences and rates in epidemiologic trends may help researchers and clinicians estimate disease burden and understand the reasons behind these differences, which may hold the key to unravel the etiology of IBD. (Intest Res 2016;14:1 11-119)

Key Words: Inflammatory bowel diseases; Colitis, ulcerative; Crohn disease; Asia; Epidemiology

\section{INTRODUCTION}

Inflammatory bowel disease (IBD) includes UC and CD. It is a chronic inflammatory disease that involves the gastrointestinal tract and results from a combination of genetic susceptibility, environmental exposure, and dysregulated responses to intestinal microbiota. ${ }^{1}$ The highest occurrence of IBD is seen in developed countries in North America and Europe, affecting up to $0.5 \%$ of the general population. ${ }^{2}$ Despite its previously low incidence, Asia has been experiencing a significant increase in IBD incidence in the past two decades, ${ }^{3,4}$ while Europe has had a plateauing or even

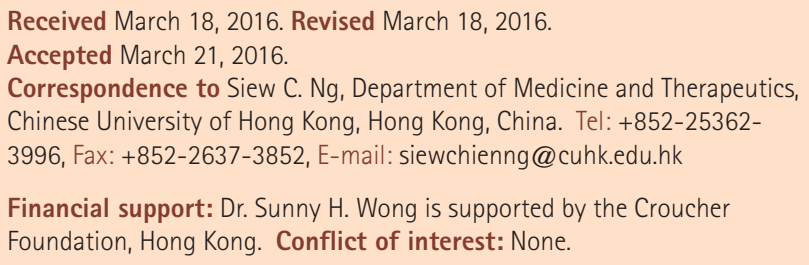

decreasing trend of incidence. ${ }^{2}$ This rapid increase in incidence, coupled to the considerable socioeconomic changes in Asia, has given rise to an opportunity to study the etiology of IBD.

\section{EPIDEMIOLOGY}

\section{Incidence}

The incidences of UC and CD are highest in the West with annual rates as high as 24.3 per 100,000 and 29.3 per 100,000 persons, respectively. ${ }^{2,5}$ Despite IBD being much less common in Asia than in the West, it is of concern that the incidence of UC and CD are rising in parallel with rapid urbanization. The highest incidence was mainly reported in East Asia (Korea, Japan, China, Hong Kong) and South Asia (India). A large-scale population-based study of 8 Asian countries (mainland China, Hong Kong, Macau, Singapore, Malaysia, Thailand, Sri Lanka and Indonesia) in 2013 (AC-

\footnotetext{
(c) Copyright 2016. Korean Association for the Study of Intestinal Diseases. All rights reserved.

This is an Open Access article distributed under the terms of the Creative Commons Attribution Non-Commercial License (http://creativecommons.org/licenses/by-nc/4.0)

which permits unrestricted non-commercial use, distribution, and reproduction in any medium, provided the original work is properly cited.
} 
CESS), has shown notable variations in IBD incidence, ranging from 0.54 to 3.44 per 100,000 persons. In this study, the highest annual incidence of IBD was seen in East Asian urbanized areas like Guangzhou (mainland China) at 3.44 per 100,000, with Hong Kong following closely behind at 3.06 per 100,000 and Macau at 2.2 per 100,000 persons. Lower rates were reported in the Southeast Asian countries. There were also notable differences in the incidence of IBD incidence within the same country. In mainland China, the IBD incidence in Guangzhou, Wuhan, Daqing, Chengdu, and Xian were $3.44,1.96,1.77,0.58$, and 0.54 per 100,000 persons, respectively. ${ }^{4,6,7}$ These differences have been attributed to the disparate levels of industrialization in these regions or variations in health care systems, including different access to healthcare. Higher UC and CD incidences have been reported in South Korea at 4.60 and 3.20 per 100,000 persons, respectively.

Nevertheless, not all developed countries in Asia share a similar incidence. It is noteworthy that even highly urbanized countries like Singapore and Malaysia have a much lower IBD incidence at 1.06 per 100,000 and 0.94 per 100,000 persons, respectively. ${ }^{4}$ This may be a consequence of the multi-ethnicity within these countries, with a varying genetic predisposition, lifestyle habits, and other possible unknown environmental factors. To help understand the incidence in different ethnic groups within a country, an analysis of the IBD incidence by race was conducted in Malaysia. The highest rate was seen in Indians (1.91 per 100,000 persons), followed by Chinese (0.63 per 100,000 persons), and Malays ( 0.35 per 100,000 persons). ${ }^{8}$ This is also in keeping with a house-to-house survey in Punjab (North India) from 1999 to 2000 , which showed a much higher incidence and prevalence rate of UC in the Punjabi populations at 6.02 and 44.3 per 100,000 persons, respectively. ${ }^{9}$ The distinction in the inter-racial IBD incidence rates supports the likelihood of genetic factors, although different lifestyle and environmental factors may exist for these different ethnic groups. These are important factors to consider when reviewing incidence and prevalence rates in multi-ethnic countries.

Furthermore, rural and urban areas within Asian countries may experience different rates in IBD increases. One such example is a recent hospital-based study in Korea from an area outside of the city of Seoul, which demonstrated lower rates of complicated disease. Long-term population-based epidemiological studies covering rural as well as urban areas within Asia would help us understand the characteristics of IBD in this region and the interregional differences. ${ }^{10}$

\section{Prevalence}

IBD is a chronic disease that involves young patients. In addition, its rapidly increasing incidence together with the better access and delivery of healthcare is resulting in an exponential growth in the prevalence of IBD in Asia. The effect of compounding prevalence ${ }^{11}$ of IBD in Asia is crucial for future healthcare planning, as existing systems in newly industrialized countries may not be ready for the staggering increase in disease burden. From 1991 to 2005, the prevalence of UC in Japan has increased by 3.5-fold from 18.1 to 63.6 per 100,000 persons, while the prevalence of CD has increased by 3 -fold from 5.9 to 21.1 per 100,000 persons. ${ }^{12,13}$ The latest information available from the Japanese National IBD registry has shown that the prevalence of $U C$ and $C D$ has increased significantly to 121.9 and 30.1 per 100,000 persons respectively in $2013 .{ }^{14}$ This observation emphasizes the importance for healthcare systems in Asia to pre-emptively invest resources in preparation for the burgeoning IBD burden.

\section{Temporal Trend}

In general, UC tends to appear first in areas with emerging IBD, followed by CD at a variable interval. In North America, the incidence of UC and CD increased from 8.3 and 6.9 per 100,000 persons, respectively, in $1993,{ }^{15}$ to 14.3 and 14.6 per 100,000 , respectively, in $2004 .{ }^{16} \mathrm{~A}$ similar trend was also observed amongst Asian countries in the past few decades. Incidences for both UC and CD were rapidly rising in Asia, with CD having a steeper increment in more developed countries, resulting in a reducing UC:CD ratio over time. A large prospective population-based epidemiological study from South Korea (Korean Association for the Study of Intestinal Diseases [KASID]) showed at least a 10-fold increase in the incidence of UC and CD over two decades. The UC and CD incidence rates increased from 0.34 and 0.05 per 100,000 persons, respectively, from 1986 to 1990 , to 3.08 and 1.34 per 100,000 persons from 2001 to 2005 . There is also a reduction in the UC to CD ratio from 6.8 to 2.3 during the same period, demonstrating a sharper rise in CD incidence over time. ${ }^{17}$ More recent Korean data have reported that the incidence of UC and CD have further increased to 5.0 and 3.6 per 100,000 persons, respectively, in 2006. Within this same study, both the incidence of UC and CD were observed to have stabilized and perhaps are showing a slight reduction trend; the most recent incidence for UC and CD in 2012 was 4.2 and 3.1 per 100,000 persons, respectively. ${ }^{18}$

Table 1 summarises the available incidence and preva- 
Table 1. Incidence and Prevalence Rates of IBD in Various Asian Countries

\begin{tabular}{|c|c|c|c|c|c|c|}
\hline \multirow[t]{2}{*}{ Country } & \multirow[t]{2}{*}{ Period } & \multicolumn{2}{|c|}{$\begin{array}{c}\text { Incidence Rate } \\
\text { (per } 100,000 \text { persons) }\end{array}$} & \multirow[t]{2}{*}{$\mathrm{UC} / \mathrm{CD}$} & \multicolumn{2}{|c|}{$\begin{array}{c}\text { Prevalence Rate } \\
\text { (per 100,000 persons) }\end{array}$} \\
\hline & & UC & CD & & UC & CD \\
\hline \multirow[t]{5}{*}{ Korea } & $1986-1990^{17}$ & $0.34^{a}$ & $0.05^{a}$ & 6.8 & - & - \\
\hline & $1991-1995^{17}$ & $0.87^{\mathrm{a}}$ & $0.22^{\mathrm{a}}$ & 3.9 & - & - \\
\hline & $1996-2000^{17}$ & $1.74^{\mathrm{a}}$ & $0.52^{\mathrm{a}}$ & 3.3 & 7.60 & - \\
\hline & $2001-2005^{17}$ & $3.08^{\mathrm{a}}$ & $1.34^{\mathrm{a}}$ & 2.3 & 30.90 & 11.20 \\
\hline & $2006-2012^{18}$ & 4.60 & 3.20 & 1.4 & - & - \\
\hline \multirow[t]{4}{*}{ Japan } & $1965^{19}$ & 0.08 & 0.01 & 8.0 & 5.50 & 0.88 \\
\hline & $1991^{12}$ & 1.95 & 0.51 & 3.8 & 18.10 & 5.90 \\
\hline & $2005^{13}$ & - & - & - & $63.60^{b}$ & $21.10^{b}$ \\
\hline & $2013^{14}$ & - & - & - & 121.90 & 30.10 \\
\hline Mainland China (Guangzhou) & $2011-2012^{4}$ & 2.22 & 1.22 & 1.8 & - & - \\
\hline Mainland China (Wuhan) & $2010-2011^{6}$ & 1.59 & 0.56 & 2.8 & - & - \\
\hline Mainland China (Daqing) & $2012-2013^{7}$ & 1.64 & 0.13 & 12.6 & - & - \\
\hline Mainland China (Chengdu) & $2011-2012^{4}$ & 0.43 & 0.14 & 3.0 & - & - \\
\hline Mainland China (Xian) & $2011-2012^{4}$ & 0.42 & 0.07 & 6.0 & - & - \\
\hline \multirow[t]{3}{*}{ Hong Kong } & $1990-1992^{20}$ & 0.80 & 0.40 & 2.0 & - & - \\
\hline & $1999-2001^{20}$ & 1.20 & 1.00 & 1.2 & - & - \\
\hline & $2011-2012^{4}$ & 1.66 & 1.31 & 1.2 & - & - \\
\hline Macau & $2011-2012^{4}$ & 1.00 & 0.60 & 1.7 & - & - \\
\hline Sri Lanka & $2011-2012^{4}$ & 0.95 & 0.59 & 1.6 & - & - \\
\hline Taiwan & $2000-2010^{21}$ & 0.84 & 0.21 & 3.9 & - & - \\
\hline Singapore & $2011-2012^{4}$ & 0.61 & 0.40 & 1.5 & - & - \\
\hline Malaysia & $2011-2013^{4,8}$ & 0.59 & 0.24 & 2.5 & 6.67 & 2.17 \\
\hline Indonesia & $2011-2012^{4}$ & 0.55 & 0.33 & 1.7 & - & - \\
\hline Thailand (Chiangmai) & $2011-2012^{4}$ & 0.36 & 0.30 & 1.2 & - & - \\
\hline Thailand (Bangkok) & $2011-2012^{4}$ & 0.35 & 0.28 & 1.3 & - & - \\
\hline India (Punjab) & $1999-2000^{9}$ & 6.02 & - & - & 44.30 & - \\
\hline
\end{tabular}

${ }^{\mathrm{a}}$ Age and sex-standardized rates.

${ }^{b}$ Age standardized rate.

lence rates of IBD in various Asian countries.

\section{GENETIC FACTORS}

There is varying genetic predisposition to IBD in different regions. Major nucleotide oligomerisation domain (NOD2) variants in Caucasians have not been identified in many of the Asian ethnicities (Han Chinese, Japanese, Korean, Indian and Malaysians). ${ }^{22}$ However, novel NOD2 mutations associated with CD have been reported in Malaysians (JW1 mutation) and Han Chinese and Indians (P268S mutation). ${ }^{23}$ Amongst Asian populations, tumor necrosis factor super- family 15 (TNFSF15) polymorphisms are associated with $\mathrm{CD}$, while the $T N F \alpha-308$ polymorphism is associated with UC. A recent large-scale trans-ethnic study has also demonstrated the significant genetic heterogeneity between East Asian, Indian, and Iranian populations in Asia. ${ }^{24}$ Identification of novel genes and genetic variants in Asian patients will help us comprehend the genotype to phenotype contribution to IBD's disease course and also explain the differing genetic predisposition between ethnicities.

While genetic factors are important in the pathogenesis of IBD, genetic predilection alone is insufficient to result in disease manifestation. Studies of monozygotic twins report a 
concordance rate for $\mathrm{CD}$ ranging from $20 \%$ to $50 \%$ and a much lower rate for $\mathrm{UC}^{25-27}$ advocating for the presence of other important environmental factors in the development of IBD.

\section{ENVIRONMENTAL FACTORS}

Environmental factors play an integral role in IBD pathogenesis. A prospective study evaluating South Asian immigrants to Leicester, United Kingdom (UK), has shown that UK born children of South Asian descent had a comparable risk of developing UC as the local population, ${ }^{28}$ despite having lower rates of UC in their native countries. Such studies have been pivotal in substantiating the role of environmental factors in the development of IBD. ${ }^{29,30}$ A more recent retrospective study of a population-based cohort of IBD patients in Ontario, Canada, has reported the association of younger age of immigration to Canada and an increased risk of IBD ( $14 \%$ increased risk per younger decade of life at immigration). Canadian-born children of immigrants from some regions (Middle East/North Africa, South Asia, Sub-Saharan Africa) assumed an equally high IBD incidence as children of non-immigrants, supporting the importance of early-life environmental exposures in the development of IBD. ${ }^{31,32}$

\section{Smoking}

Western studies reported smoking as a consistent factor associated with IBD, increasing the risk of CD but reducing the risk of UC. ${ }^{33-36}$ Furthermore, actively smoking CD patients undergo a worse disease trajectory, with a higher risk of relapse after remission. On the contrary, UC patients are more likely to have a disease flare after smoking cessation. ${ }^{37}$ It appears that smoking does not have such a marked impact on Asian CD patients. At a population level, Western countries like Canada and Sweden with a high CD incidence have a lower prevalence of smoking in the adult population $(<30 \%)$. In comparison to Asian countries with a much higher smoking prevalence ( $>65 \%$ of men), a much lower CD incidence has been reported. This observation suggests that although smoking is an important risk factor for CD, it could only influence the disease course but may not be sufficient to affect population trends in IBD. ${ }^{38}$

\section{Appendectomy}

Asian studies from Japan ${ }^{39}$ and China ${ }^{40}$ have shown that appendectomy is associated with a decreased risk of developing UC, similar to the Western data. ${ }^{41}$ The notion of ap- pendicitis rather than appendectomy having a protective effect against UC in the Western population, ${ }^{42,43}$ does not have any corroborative data in Asia. Currently, there is no convincing evidence to associate appendectomy to the development of CD.

\section{Diet}

Several studies from the West have reported that increased consumption of linoleic acid ${ }^{44}$ and animal protein ${ }^{45}$ are associated with an increased risk of IBD, especially for UC in healthy women. Increased intake of fats, fatty acids, sugar, and meat are correlated with an increased risk of UC relapse. ${ }^{46}$ High sugar consumption has also been reported to increase the predisposition to develop $\mathrm{CD}^{47}$ On the contrary, increased fiber, fruit, and vegetable intake seem to reduce the risk of IBD development. ${ }^{48}$ Studies from Japan have reported similar findings, showing that increased intake of sweets, fats, fatty acids, meat, and oil correlate with the increased risk of developing IBD. ${ }^{49,50}$ A recent case control population-based study involving 9 different Asia Pacific countries (ACCESS) has reported that more than 12 months of breast feeding has a marked protective effect on the development of both UC and CD. Consumption of tea or coffee has also been noted to have a protective effect $^{51}$ against IBD.

\section{Antibiotics Usage}

Several observational studies from the West have shown an association between antibiotic usage and the subsequent diagnosis of IBD, although the causality has not been proven. ${ }^{52-54}$ In contrast, the only available Asian study has reported a protective effect of childhood antibiotics against the development of UC and CD. This paradoxical effect might be a consequence of childhood antibiotics usage being a surrogate for gastrointestinal infections, which in turn result in the induction of tolerance. ${ }^{51}$

\section{CLINICAL PRESENTATION}

Many of the clinical manifestations of IBD in Asia share similar characteristics to patients in the West. Nonetheless, there are several notable differences that are relevant to physicians.

\section{Sex}

There seems to be an overall female preponderance for IBD in the Western literature. ${ }^{55,56}$ In Canada, the women to 
men incidence rate ratio can be as high as 1.53 for $\mathrm{CD}$ and 1.21 for UC in certain provinces. ${ }^{55}$ However, what is more consistently observed is the female preponderance for CD but an equal or slight female preponderance in UC. On the contrary, Asian data seem to support a male preponderance for $\mathrm{CD}$, but an equal or slight male preponderance for UC. The men to women ratio in Asia for CD was as high as 2.83. . $^{17,20,21,57,58}$ Thus far, there has not been a proven cause for such a phenomenon. Possibilities would include a different genetic susceptibility and men having greater chances to seek education or job opportunities in industrialized areas at a younger age, which increases their early-life exposure to potential environmental risk factors. Continued monitoring of the epidemiological evolution in Asia will be important to detect any reversal of the sex ratio over time, to parallel that of Western data.

\section{Age}

Multiple Western studies have reported a bimodal distribution in the age at diagnosis of IBD patients, with a younger peak age at 20 to 30 years for $\mathrm{CD}, 30$ to 40 years for UC, and a lower second older peak at 60 to 70 years for both diseases. ${ }^{59}$ This bimodal distribution by age has not been consistently reported in Asia, with several newer Asian studies demonstrating only the presence of a first peak at a comparable younger age and a much less prominent second peak., ${ }^{9,17,20,60,61}$

\section{Disease Presentation and Course}

Clinical presentations for UC are comparable between Asian and Western populations, with some Chinese data reporting a milder disease course and less fulminant colitis. ${ }^{60,61}$ More differences are noted between Asian CD patients and their Western counterparts. Ileal, colonic, and ileocolonic involvement are usually found in equal proportions in the Western CD population. Data from East Asia has observed that ileocolonic disease is the most common CD phenotype, with $71.0 \%$ in Guangdong (China) ${ }^{62} 66.7 \%$ in South Korea, ${ }^{17} 65.8 \%$ in Japan, ${ }^{63}$ and $50.5 \%$ in Hong Kong. ${ }^{64}$ More heterogeneity in CD disease involvement is noted in South and West Asia. ${ }^{61,65}$ Of significance, perianal disease is commonly detected in East Asian patients, involving 58.8\% of CD patients in Guangdong (China), ${ }^{62} 43.1 \%$ in Korea, ${ }^{66}$ and $30.3 \%$ in Hong Kong. ${ }^{64}$ This is higher than the Caucasian CD data, with reported rates in CD patients with perianal disease up to $29.6 \%$ in a multi-center American and European study, ${ }^{67} 26.6 \%$ in New Zealand, ${ }^{68}$ and $25.1 \%$ in France. ${ }^{69}$ It has also been reported that colectomy rates for UC and CD are lower in Asia ( $1 \%$ at 1 year), with the exact reason yet to be determined. Postulations included a milder UC course and a higher threshold to perform colectomy in Asia. ${ }^{65,70}$

\section{Family History}

Familial aggregation among IBD patients is commonly reported in the Western population, and is more frequently noted in CD than UC. ${ }^{71-74}$ A systematic review has noted that $0 \%$ to $3.4 \%$ of Asian IBD patients have familial aggregation, which is much lower than the reported rates of $10 \%$ to $25 \%$ in Western countries. ${ }^{75}$

\section{Extra-intestinal Manifestations (EIM)}

There is a significant variation in the prevalence of EIM in Asia, with the highest reported prevalence in India, involving around one-third of the IBD patients. ${ }^{75,76}$ In contrast, the reported prevalence of EIM in East Asia is significantly lower at $6 \%$ to $14 \%,{ }^{65}$ compared to $21 \%$ to $41 \%$ in the West. $^{77-79}$

\section{Colorectal Cancer (CRC)}

Available Asian data indicates a lower overall prevalence rate of $2.2 \%$ of UC related $\mathrm{CRC}^{40,64,80-83}$ compared to the $3 \%$ to $5 \%$ in the West. ${ }^{84,85}$ However, it is important to note that the available Asian studies have shorter durations of followup. Other contributory factors for lower reported CRC rates in Asia include the shorter UC history in the region and also relatively lower disease prevalence. It is probable that the prevalence of UC-related CRC will increase in parallel with the increasing disease prevalence and duration of disease in Asia.

\section{Older-onset IBD}

Older-onset IBD refers to patients diagnosed with IBD at an age above 60 years. Studies from Western countries have generally reported a less aggressive course of IBD, ${ }^{86}$ especially for UC. ${ }^{86-88}$ In contrast, Asian older-onset UC patients tend to have a similar, ${ }^{89}$ if not worse, outcome than the younger-onset UC patients. ${ }^{90,91}$ A Hong Kong retrospective population-based study has reported that older-onset UC is associated with a higher risk of suffering from opportunistic infections like cytomegalovirus and Clostridium difficile, higher rates of hospitalization for UC flares, CRC, all-cause mortality, and UC-related mortality compared to youngeronset patients. ${ }^{90}$ This disparate clinical course is clinically 
important, because it accentuates that the available Western data do not necessarily translate to similar trends in Asia. This finding advocates for ongoing Asian IBD epidemiological studies to detect such dissimilarities.

A recent systematic review and meta-analysis of available studies worldwide has observed that older-onset CD patients are more likely to have isolated colonic involvement, which are predominantly inflammatory in nature and are infrequently associated with perianal disease. Older-onset UC is more similar to younger-onset UC, with a slightly higher likelihood of left sided colitis but not pancolitis. Although immunomodulators and biologics are less commonly used in olderonset IBD patients, this was not supported by lower surgical rates. On the contrary, older-onset UC patients have higher rates of surgery, suggesting that the disease course for olderonset IBD is not more benign than younger-onset disease. ${ }^{92}$

\section{CONCLUSIONS}

An exponential increase in the prevalence of IBD within Asia is of concern and it is imperative that Asian healthcare systems are prepared for this. Despite this being the same condition afflicting both Western and Asian populations, there are several significant variations in its phenotype, possibly as a result of the differences in genetic composition and environmental influences. Physicians should be cognizant of these differences and be prepared to individualize management for their patients. Evaluating the differences between Asian and Western IBD data will help us better understand the etiology of IBD. Well-conducted epidemiological studies in more areas with different rates of urbanization within Asia are essential for us to achieve this goal.

\section{REFERENCES}

1. Danese S, Fiocchi C. Etiopathogenesis of inflammatory bowel diseases. World J Gastroenterol 2006;12:4807-4812.

2. Molodecky NA, Soon IS, Rabi DM, et al. Increasing incidence and prevalence of the inflammatory bowel diseases with time, based on systematic review. Gastroenterology 2012;142:46-54.

3. Thia KT, Loftus EV, Jr., Sandborn WJ, Yang SK. An update on the epidemiology of inflammatory bowel disease in Asia. Am J Gastroenterol 2008;103:3167-3182.

4. Ng SC, Tang W, Ching JY, et al. Incidence and phenotype of inflammatory bowel disease based on results from the Asiapacific Crohn's and colitis epidemiology study. Gastroenterology 2013;145:158-165.
5. Cosnes J, Gower-Rousseau C, Seksik P, Cortot A. Epidemiology and natural history of inflammatory bowel diseases. Gastroenterology 2011;140:1785-1794.

6. Zhao J, Ng SC, Lei Y, et al. First prospective, population-based inflammatory bowel disease incidence study in mainland of China: the emergence of "western" disease. Inflamm Bowel Dis 2013;19:1839-1845.

7. Yang H, Li Y, Wu W, et al. The incidence of inflammatory bowel disease in Northern China: a prospective populationbased study. PLoS One 2014;9:e101296. doi: 10.1371/journal. pone.0101296.

8. Hilmi I, Jaya F, Chua A, Heng WC, Singh H, Goh KL. A first study on the incidence and prevalence of IBD in Malaysia-results from the Kinta Valley IBD Epidemiology Study. J Crohns Colitis 2015;9:404-409.

9. Sood A, Midha V, Sood N, Bhatia AS, Avasthi G. Incidence and prevalence of ulcerative colitis in Punjab, North India. Gut 2003;52:1587-1590.

10. Lee EJ, Kim TO, Song GA, et al. Clinical features of Crohn's disease in Korean patients residing in Busan and Gyeongnam. Intest Res 2016;14:30-36.

11. Kaplan GG. The global burden of IBD: from 2015 to 2025. Nat Rev Gastroenterol Hepatol 2015;12:720-727.

12. Morita N, Toki S, Hirohashi T, et al. Incidence and prevalence of inflammatory bowel disease in Japan: nationwide epidemiological survey during the year 1991. J Gastroenterol 1995;30(Suppl 8):1-4.

13. Asakura K, Nishiwaki Y, Inoue N, Hibi T, Watanabe M, Takebayashi T. Prevalence of ulcerative colitis and Crohn's disease in Japan. J Gastroenterol 2009;44:659-665.

14. Japanese Ministry of Health, Labour and Welfare. Handbook of Health and Welfare Statistics 2014 Contents. Table 2-22 Number of persons with specific (intractable) disease healthcare certificate by disease and sex. http://www.mhlw.go.jp/english/ database/db-hh/2-1.html.

15. Loftus EV, Jr. Clinical epidemiology of inflammatory bowel disease: Incidence, prevalence, and environmental influences. Gastroenterology 2004;126:1504-1517.

16. Kappelman MD, Rifas-Shiman SL, Kleinman K, et al. The prevalence and geographic distribution of Crohn's disease and ulcerative colitis in the United States. Clin Gastroenterol Hepatol 2007;5:1424-1429.

17. Yang SK, Yun S, Kim JH, et al. Epidemiology of inflammatory bowel disease in the Songpa-Kangdong district, Seoul, Korea, 1986-2005: a KASID study. Inflamm Bowel Dis 2008;14:542-549.

18. Kim HJ, Hann HJ, Hong SN, et al. Incidence and natural course of inflammatory bowel disease in Korea, 2006-2012: a nationwide population-based study. Inflamm Bowel Dis 2015;21:623-630. 
19. Yoshida Y, Murata Y. Inflammatory bowel disease in Japan: studies of epidemiology and etiopathogenesis. Med Clin North Am 1990;74:67-90.

20. Leong RW, Lau JY, Sung JJ. The epidemiology and phenotype of Crohn's disease in the Chinese population. Inflamm Bowel Dis 2004;10:646-651.

21. Kuo CJ, Yu KH, See LC, et al. The trend of inflammatory bowel diseases in Taiwan: a population-based study. Dig Dis Sci 2015;60:2454-2462.

22. Ng SC, Tsoi KK, Kamm MA, et al. Genetics of inflammatory bowel disease in Asia: systematic review and meta-analysis. Inflamm Bowel Dis 2012;18:1164-1176.

23. Chua KH, Hilmi I, Ng CC, et al. Identification of NOD2/CARD15 mutations in Malaysian patients with Crohn's disease. J Dig Dis 2009;10:124-130.

24. Liu JZ, van Sommeren S, Huang H, et al. Association analyses identify 38 susceptibility loci for inflammatory bowel disease and highlight shared genetic risk across populations. Nat Genet 2015;47:979-986

25. Halfvarson J, Jess T, Magnuson A, et al. Environmental factors in inflammatory bowel disease: a co-twin control study of a Swedish-Danish twin population. Inflamm Bowel Dis 2006;12:925-933.

26. Orholm M, Binder V, Sørensen TI, Rasmussen LP, Kyvik KO. Concordance of inflammatory bowel disease among Danish twins. Results of a nationwide study. Scand J Gastroenterol 2000;35:1075-1081.

27. Thompson NP, Driscoll R, Pounder RE, Wakefield AJ. Genetics versus environment in inflammatory bowel disease: results of a British twin study. BMJ 1996;312:95-96.

28. Carr I, Mayberry JF. The effects of migration on ulcerative colitis: a three-year prospective study among Europeans and firstand second- generation South Asians in Leicester (1991-1994). Am J Gastroenterol 1999;94:2918-2922.

29. Jayanthi V, Probert CS, Pinder D, Wicks AC, Mayberry JF. Epidemiology of Crohn's disease in Indian migrants and the indigenous population in Leicestershire. Q J Med 1992;82:125-138.

30. Probert CS, Jayanthi V, Pinder D, Wicks AC, Mayberry JF. Epidemiological study of ulcerative proctocolitis in Indian migrants and the indigenous population of Leicestershire. Gut 1992;33:687-693.

31. Benchimol EI, Mack DR, Guttmann A, et al. Inflammatory bowel disease in immigrants to Canada and their children: a population-based cohort study. Am J Gastroenterol 2015;110:553-563.

32. Benchimol EI, Manuel DG, To T, et al. Asthma, type 1 and type 2 diabetes mellitus, and inflammatory bowel disease amongst South Asian immigrants to Canada and their children: a population-based cohort study. PLoS One 2015;10:e0123599. doi: 10.1371/journal.pone.0123599.
33. van der Heide F, Dijkstra A, Weersma RK, et al. Effects of active and passive smoking on disease course of Crohn's disease and ulcerative colitis. Inflamm Bowel Dis 2009;15:1199-1207.

34. Calkins BM. A meta-analysis of the role of smoking in inflammatory bowel disease. Dig Dis Sci 1989;34:1841-1854.

35. Boyko EJ, Koepsell TD, Perera DR, Inui TS. Risk of ulcerative colitis among former and current cigarette smokers. N Engl J Med 1987;316:707-710.

36. Sutherland LR, Ramcharan S, Bryant H, Fick G. Effect of cigarette smoking on recurrence of Crohn's disease. Gastroenterology 1990;98:1123-1128.

37. Cosnes J, Beaugerie L, Carbonnel F, Gendre JP. Smoking cessation and the course of Crohn's disease: an intervention study. Gastroenterology 2001;120:1093-1099.

38. Prideaux L, Kamm MA, De Cruz P, et al. Comparison of clinical characteristics and management of inflammatory bowel disease in Hong Kong versus Melbourne. J Gastroenterol Hepatol 2012;27:919-927.

39. Naganuma M, Iizuka B, Torii A, et al. Appendectomy protects against the development of ulcerative colitis and reduces its recurrence: results of a multicenter case-controlled study in Japan. Am J Gastroenterol 2001;96:1123-1126.

40. Jiang L, Xia B, Li J, et al. Risk factors for ulcerative colitis in a Chinese population: an age-matched and sex-matched casecontrol study. J Clin Gastroenterol 2007;41:280-284.

41. Koutroubakis IE, Vlachonikolis IG, Kouroumalis EA. Role of appendicitis and appendectomy in the pathogenesis of ulcerative colitis: a critical review. Inflamm Bowel Dis 2002;8:277-286.

42. Frisch M, Pedersen BV, Andersson RE. Appendicitis, mesenteric lymphadenitis, and subsequent risk of ulcerative colitis: cohort studies in Sweden and Denmark. BMJ 2009;338:b716. doi: 10.1136/bmj.b716.

43. Beaugerie L, Sokol H. Appendicitis, not appendectomy, is protective against ulcerative colitis, both in the general population and first-degree relatives of patients with IBD. Inflamm Bowel Dis 2010;16:356-357.

44. IBD in EPIC Study Investigators, Tjonneland A, Overvad K, et al. Linoleic acid, a dietary n-6 polyunsaturated fatty acid, and the aetiology of ulcerative colitis: a nested case-control study within a European prospective cohort study. Gut 2009;58:1606-1611.

45. Jantchou P, Morois S, Clavel-Chapelon F, Boutron-Ruault MC, Carbonnel F. Animal protein intake and risk of inflammatory bowel disease: The E3N prospective study. Am J Gastroenterol 2010;105:2195-2201.

46. Jowett SL, Seal CJ, Pearce MS, et al. Influence of dietary factors on the clinical course of ulcerative colitis: a prospective cohort study. Gut 2004;53:1479-1484. 
47. Riordan AM, Ruxton CH, Hunter JO. A review of associations between Crohn's disease and consumption of sugars. Eur J Clin Nutr 1998;52:229-238.

48. Hou JK, Abraham B, El-Serag H. Dietary intake and risk of developing inflammatory bowel disease: a systematic review of the literature. Am J Gastroenterol 2011;106:563-573.

49. Shoda R, Matsueda K, Yamato S, Umeda N. Epidemiologic analysis of Crohn disease in Japan: increased dietary intake of n-6 polyunsaturated fatty acids and animal protein relates to the increased incidence of Crohn disease in Japan. Am J Clin Nutr 1996;63:741-745.

50. Sakamoto N, Kono S, Wakai K, et al. Dietary risk factors for inflammatory bowel disease: a multicenter case-control study in Japan. Inflamm Bowel Dis 2005;11:154-163.

51. Ng SC, Tang W, Leong RW, et al. Environmental risk factors in inflammatory bowel disease: a population-based case-control study in Asia-Pacific. Gut 2015;64:1063-1071.

52. Virta L, Auvinen A, Helenius H, Huovinen P, Kolho KL. Association of repeated exposure to antibiotics with the development of pediatric Crohn's disease-a nationwide, register-based finnish case-control study. Am J Epidemiol 2012;175:775-784.

53. Shaw SY, Blanchard JF, Bernstein CN. Association between the use of antibiotics and new diagnoses of Crohn's disease and ulcerative colitis. Am J Gastroenterol 2011;106:2133-2142.

54. Hviid A, Svanström H, Frisch M. Antibiotic use and inflammatory bowel diseases in childhood. Gut 2011;60:49-54.

55. Bernstein CN, Wajda A, Svenson LW, et al. The epidemiology of inflammatory bowel disease in Canada: a population-based study. Am J Gastroenterol 2006;101:1559-1568.

56. Vind I, Riis L, Jess T, et al. Increasing incidences of inflammatory bowel disease and decreasing surgery rates in Copenhagen City and County, 2003-2005: a population-based study from the Danish Crohn colitis database. Am J Gastroenterol 2006;101:1274-1282.

57. Yao T, Matsui T, Hiwatashi N. Crohn's disease in Japan: diagnostic criteria and epidemiology. Dis Colon Rectum 2000;43(10 Suppl):S85-S93.

58. Jiang L, Xia B, Li J, et al. Retrospective survey of 452 patients with inflammatory bowel disease in Wuhan city, central China. Inflamm Bowel Dis 2006;12:212-217.

59. Loftus EV, Jr., Sandborn WJ. Epidemiology of inflammatory bowel disease. Gastroenterol Clin North Am 2002;31:1-20.

60. Jiang XL, Cui HF. An analysis of 10218 ulcerative colitis cases in China. World J Gastroenterol 2002;8:158-161.

61. Wang YF, Zhang H, Ouyang Q. Clinical manifestations of inflammatory bowel disease: East and West differences. J Dig Dis 2007;8:121-127.
62. Zeng Z, Zhu Z, Yang Y, et al. Incidence and clinical characteristics of inflammatory bowel disease in a developed region of Guangdong Province, China: a prospective population-based study. J Gastroenterol Hepatol 2013;28:1148-1153.

63. Oriuchi T, Hiwatashi N, Kinouchi Y, et al. Clinical course and longterm prognosis of Japanese patients with Crohn's disease: predictive factors, rates of operation, and mortality. J Gastroenterol 2003;38:942-953.

64. Chow DK, Leong RW, Lai LH, et al. Changes in Crohn's disease phenotype over time in the Chinese population: validation of the Montreal classification system. Inflamm Bowel Dis 2008;14:536-541.

65. Ng SC. Epidemiology of inflammatory bowel disease: focus on Asia. Best Pract Res Clin Gastroenterol 2014;28:363-372.

66. Park SH, Yang SK, Park SK, et al. Long-term prognosis of Crohn's disease and its temporal change between 1981 and 2012: a hospital-based cohort study from Korea. Inflamm Bowel Dis 2014;20:488-494.

67. Sachar DB, Bodian CA, Goldstein ES, et al. Is perianal Crohn's disease associated with intestinal fistulization? Am J Gastroenterol 2005;100:1547-1549.

68. Eglinton TW, Barclay ML, Gearry RB, Frizelle FA. The spectrum of perianal Crohn's disease in a population-based cohort. Dis Colon Rectum 2012;55:773-777.

69. Beaugerie L, Seksik P, Nion-Larmurier I, Gendre JP, Cosnes J. Predictors of Crohn's disease. Gastroenterology 2006;130:650-656.

70. Prideaux L, Kamm MA, De Cruz PP, Chan FK, Ng SC. Inflammatory bowel disease in Asia: a systematic review. J Gastroenterol Hepatol 2012;27:1266-1280.

71. Orholm M, Munkholm P, Langholz E, Nielsen OH, Sorensen TI, Binder V. Familial occurrence of inflammatory bowel disease. N Engl J Med 1991;324:84-88.

72. Peeters M, Nevens H, Baert F, et al. Familial aggregation in Crohn's disease: increased age-adjusted risk and concordance in clinical characteristics. Gastroenterology 1996;111:597-603.

73. Yang H, McElree C, Roth MP, Shanahan F, Targan SR, Rotter JI. Familial empirical risks for inflammatory bowel disease: differences between Jews and non-Jews. Gut 1993;34:517-524.

74. Roth MP, Petersen GM, McElree C, Vadheim CM, Panish JF, Rotter JI. Familial empiric risk estimates of inflammatory bowel disease in Ashkenazi Jews. Gastroenterology 1989;96:1016-1020.

75. Kochhar R, Mehta SK, Nagi B, Bhatia V, Goenka MK, Malik AK. Extraintestinal manifestations of idiopathic ulcerative colitis. Indian J Gastroenterol 1991;10:88-89.

76. Bandyopadhyay D, Bandyopadhyay S, Ghosh P, et al. Extraintestinal manifestations in inflammatory bowel disease: Prevalence and predictors in Indian patients. Indian J Gastroenterol 2015;34:387-394. 
77. Greenstein AJ, Janowitz HD, Sachar DB. The extra-intestinal complications of Crohn's disease and ulcerative colitis: a study of 700 patients. Medicine (Baltimore) 1976;55:401-412.

78. Monsén U, Sorstad J, Hellers G, Johansson C. Extracolonic diagnoses in ulcerative colitis: an epidemiological study. Am J Gastroenterol 1990;85:711-716.

79. Rankin GB, Watts HD, Melnyk CS, Kelley ML, Jr. National Cooperative Crohn's Disease Study: extraintestinal manifestations and perianal complications. Gastroenterology 1979;77:914-920.

80. Ling KL, Ooi CJ, Luman W, Cheong WK, Choen FS, Ng HS. Clinical characteristics of ulcerative colitis in Singapore, a multiracial city-state. J Clin Gastroenterol 2002;35:144-148.

81. Fujimoto T, Kato J, Nasu J, et al. Change of clinical characteristics of ulcerative colitis in Japan: analysis of 844 hospitalbased patients from 1981 to 2000. Eur J Gastroenterol Hepatol 2007;19:229-235.

82. Kim BJ, Yang SK, Kim JS, et al. Trends of ulcerative colitis-associated colorectal cancer in Korea: A KASID study. J Gastroenterol Hepatol 2009;24:667-671.

83. Fujita T, Ando T, Watanabe O, et al. Clinicopathological study of colorectal cancer occurring in patients with ulcerative colitis: results from a single hospital in Japan. Hepatogastroenterology 2010;57:487-492.

84. Dobbins WO, 3rd. Dysplasia and malignancy in inflammatory bowel disease. Annu Rev Med 1984;35:33-48.

85. Eaden JA, Abrams KR, Mayberry JF. The risk of colorectal cancer in ulcerative colitis: a meta-analysis. Gut 2001;48:526-535.
86. Charpentier C, Salleron J, Savoye G, et al. Natural history of elderly-onset inflammatory bowel disease: a population-based cohort study. Gut 2014;63:423-432.

87. Riegler G, Tartaglione MT, Carratú R, et al. Age-related clinical severity at diagnosis in 1705 patients with ulcerative colitis: a study by GISC (Italian Colon-Rectum Study Group). Dig Dis Sci 2000;45:462-465.

88. Triantafillidis JK, Emmanouilidis A, Pomonis E, et al. Ulcerative colitis in the elderly: clinical patterns and outcome in 51 Greek patients. J Gastroenterol 2001;36:312-316.

89. Lee JH, Cheon JH, Moon CM, et al. Do patients with ulcerative colitis diagnosed at a young age have more severe disease activity than patients diagnosed when older? Digestion 2010;81:237243.

90. Shi HY, Chan FK, Leung WK, et al. Natural history of elderlyonset ulcerative colitis: results from a territory-wide inflammatory bowel disease registry. J Crohns Colitis 2016;10:176-185.

91. Matsumoto S, Miyatani H, Yoshida Y. Ulcerative colitis: comparison between elderly and young adult patients and between elderly patients with late-onset and long-standing disease. Dig Dis Sci 2013;58:1306-1312.

92. Ananthakrishnan AN, Shi HY, Tang W, et al. Systematic review and meta-analysis: phenotype and clinical outcomes of olderonset inflammatory bowel disease [published online ahead of print February 29, 2016]. J Crohns Colitis. doi: http://dx.doi. org/10.1093/ecco-jcc/jjw054. 